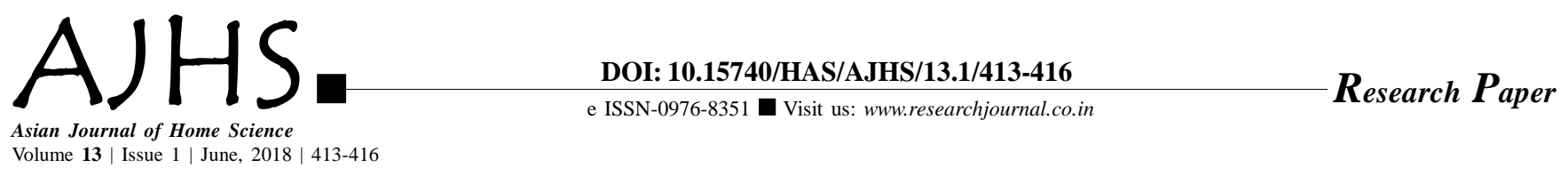

\title{
Association between nutritional status and gender among Tribal Primary School Children
}

Received: 22.02.2018; Revised: 08.05.2018; Accepted: 25.05.2018

See end of the paper for authors' affiliations Aprajita Raj

Department of Human

Development, Home Science

College and Research Institute,

Tamil Nadu Agricultural

University, Madurai (T.N.) India

Email : faboulousaprajitaraj.123

@gmail.com
ABSTRACT : Children are the wealth of a nation as they constitute one of the most important segments of the population. About 375 million children live in India, which constitutes 41 per cent of the total population. Tribal communities are one of the deprived sections of the population in all indicators of development. Tribes are found to be socially and economically deprived and their diet appears to be nutritionally deficient. Jharkhand is having $8.29 \%$ of the total tribal population and $32 \%$ of the children are undernourished in this state which reveals that one in every four children are severely underweight in this state.Hence, an attempt was made to study the association between nutritional status and gender among East Singhbhum district of Jharkhand state. The samples were comprised of 60 boys and 60 girls between the age groups of 7-11 years. Nutritional status was assessed through anthropometric measurements (height, weight) and dietary survey. These nutritional status parameters were then compared with $50^{\text {th }}$ per centile of National Centre for Health Statistics (NCHS) reference and ICMR (RDA) standards. It was found that there is a significant relationship between nutritional status and gender (both boys and girls) in all the nutritional parameters which reveals that prevalence of malnutrition was higher in girls when compared with boys.

KEY WORDS: Nutritional status, Anthropometric, Recommended dietary allowances, National Centre for Health Statistics, Indian Council of Medical Research (ICMR)

- HOW TO CITE THIS PAPER : Raj, Aprajita and Pushpa, G. (2018). Association between nutritional status and gender among Tribal Primary School Children. Asian J. Home Sci., 13 (1) : 413-416, DOI: 10.15740/HAS/AJHS/13.1/413-416. Copyright@ 2018: Hind Agri-Horticultural Society. 